\title{
Isolation And Studying of Specificity of Bacteriophages Binding To Murine Lung Adenocarcinoma
}

\author{
Mariya Borisovna Borgoyakova ${ }^{1}$, Larisa Ivanovna Karpenko ${ }^{1,2}$ and Alexander Alekseevich llyichev ${ }^{1,2 *}$ \\ ${ }^{1}$ State Research Center of Virology and Biotechnology Vector, Koltsovo, 630559, Russia \\ ${ }^{2}$ Altai State University, Barnaul, 656049, Russia
}

\begin{abstract}
The results of affinity selection in vivo from phage peptide libraries for the identification of peptides that bind to the transplantable tumor, murine lung adenocarcinoma and hepatocarcinoma, are described in this survey. Studying the affinity of the selected phages to tumor showed that they accumulated in the tumors tens and hundreds times as much as in the control organs. Absence of specific binding of phages to tumor cells in vitro allows presuming that phage accumulation in tumors in vivo is provided by interaction of peptides exposed on the surface of virion with elements of stroma.
\end{abstract}

Keywords: Phage display; Affinity selection in vivo; Murine lung adenocarcinoma; Tumor-targeted therapy

\section{Introduction}

Phage display libraries are often used to identify peptides binding to tumors. Targets for peptide selection can be represented by purified tumor antigens, cell cultures or grafted tumors [1]. By now a number of peptides have been identified that have enhanced specificity to tumors [1-5]. It was shown that phages carrying such peptides accumulate in tumor when administered intravenously. Studies was carried out both in murine models [6] and in models of human grafted tumors [2,7], and even in oncology patients [8].

There is variety of practical applications of tumor-targeted peptides obtained with the use of phage display. Some of these peptides have intrinsical antitumor activity; for instance, they can suppress functioning of tumor lymphatics [9]. It was shown that conjugation with peptides of chemotherapeutic agents, such as doxorubicin, enhances their efficiency and decrease toxicity [2]. At the same time conjugation can be performed directly with agent, or peptide can be inserted in outer membrane of liposomes or other nanoparticles transporting therapeutic agent to target $[10,11]$. Furthermore, for diagnostics purposes it is possible to conjugate tumor-targeted peptides with contrasting or fluorescent agents. It enables to localize tumors and metastases $[5,12,13]$.

Thus, peptides selected from phage peptide libraries that bind to tumors are promising candidates of targeted molecules and are able to enhance binding specificity of chemotherapeutic drugs and diagnostic agents to tumor.

The aim of this work is to select phagotopes with specificity to murine lung adenocarcinoma from phage peptide libraries.

\section{Materials and Methods}

This work was carried out with the use of 3-4-month-old male mice of A/Sn lineage obtained from vivarium of Institute of Cytology and Genetics of Siberian Branch of the Russian Academy of Sciences. All animal procedures and care were approved by the IACUC (Institutional Animal Care and Use Committee) of the State Research Center of Virology and Biotechnology Vector.

We used ascitic lung adenocarcinoma (AL) and hepatoma (HA) described previously [14]. Tumors were grafted subcutaneously in venter of experimental animals that were used in experiments when their tumor nodes grew from 5 to $8 \mathrm{~mm}$ in diameter.

To select peptides specifically interacting with AL and HA we used phage peptide libraries Ph.D.- $12^{\text {ma }}$ и Ph.D.- $7^{\text {max }}$ produced by New England Biolabs, Inc. M13mp9 phage was used as a control when studying specificity of bacteriophages to tumors. To amplify and titer phages strain Escherichia coli ER2738 was used.

Affine selection of peptides specifically interacting with tumor was carried out using previously described method of selection in vivo [2] with our modifications. Phage peptide library comprising 1011 phage particles in 0.5 DMEM medium was administered to mice' tail vein. After $5 \mathrm{~min}$ mice were put in heavy ether narcosis, opened up and $10 \mathrm{ml}$ of DMEM chilled medium was perfused through hearts. Tumors were taken out, weighted and homogenated in $1 \mathrm{ml}$ of physiological solution with $1 \mathrm{mM}$ of protease inhibitor

phenylmethylsulfonylfluoride, were washed three times with physiological solution with $1 \%$ BSA. After that tumors were incubated for $20 \mathrm{~min}$ with $1 \mathrm{ml}$ of E. coli ER2738 night culture at room temperature. After centrifugation supernatant was mixed with $20 \mathrm{ml}$ of E. coli ER2738 culture and incubated for $8 \mathrm{~h}$ at $37^{\circ} \mathrm{C}$ on thermoshaker. Obtained mix of phages was purified and used in the next selection round. After the third and the fourth rounds phages were plated, then individual phage clones were used, produced, single stranded DNA was obtained for sequencing according to instruction for a set of phage peptide libraries.

Sequencing of randomized region of DNA in selected phages was carried out using automatic capillary sequencer at Common use center "Genomics" in Siberian Branch of the Russian Academy of Sciences.

*Corresponding author: Alekseevich Ilyichev, State Research Center of Virology and Biotechnology Vector, Koltsovo, 630559, Russia, Tel: +7-383-363-48-17: Fax: +7-383-336-74-09: E-mail: ilyichev@mail.ru

Received December 01, 2014; Accepted December 31, 2014; Published January 08, 2015

Citation: Borgoyakova MB, Karpenko LI, llyichev AA (2015) Isolation And Studying of Specificity of Bacteriophages Binding To Murine Lung Adenocarcinoma. Biol Med S2: 002. doi: 10.4172/0974-8369.S2-002

Copyright: (c) 2015 Borgoyakova MB, et al. This is an open-access article distributed under the terms of the Creative Commons Attribution License, which permits unrestricted use, distribution, and reproduction in any medium, provided the original author and source are credited. 
Citation: Borgoyakova MB, Karpenko LI, Ilyichev AA (2015) Isolation And Studying of Specificity of Bacteriophages Binding To Murine Lung Adenocarcinoma. Biol Med S2: 002. doi: 10.4172/0974-8369.S2-002

Amino acid sequence of peptides exposed on the surface of phage particles was detected using analysis of results of DNA sequencing.

Analysis of selected phages distribution in organs was carried out after animals were administered with individual phage clones in quantity 109 particles in $500 \mathrm{mcl}$ of physiological solution. After 24 $\mathrm{h}$ of incubation tumor and studied organ tissues were sampled and quantity of phages was detected. For the purpose $1 \mathrm{mg}$ of tissue was homogenated, all phages that did not bind were deleted using 5-fold washing in TBS-Tween-20. Specifically bound phages were eluted using $0.2 \mathrm{M}$ Glycine-HCL/0.1\% BSA, PH 2.2. The titer of eluted phages was detected using E. coli ER2738.

Analysis of binding of selected phages to tumor cells in vitro. 106 of tumor cells washed free from ascitic fluid, and 109 of phage particles were incubated in DMEM medium at room temperature for $5 \mathrm{~min}$. After incubation cells were washed free from phages that did not bind two times. Specifically bound phages were eluted using $0.2 \mathrm{M}$ GlycineHCL/0.1\% BSA, PH 2.2. The titer of eluted phages was detected using E. coli ER2738.

\section{Results}

When selecting using adenocarcinoma from 12-mer library after four rounds of affine selection, we selected 31 phage clones of which two clones were used in our further study: with insertions TAAPVPKGPVSP and MQAAYTPPLGSL (marked as 12-1 and 12-2, respectively). When selecting using adenocarcinoma and 7-mer library, we detected sequences of 90 phages of which five clones were selected for further study: with insertions TPWPRLN, GNTPSRA, HAIYPRH, STASYTR, and STPQTPR (7-1, 7-2, 7-3, 7-8, 7-9, respectively). Specified phages were selected according to the frequency of insertions occurrence among selected phages.

To analyze distribution of phages in organisms of laboratory animals with grafted tumor AL mice were administered with individual clones of bacteriophages 12-1, 12-2, 7-1, 7-2, 7-3, 7-8, and 7-9, each of them in quantity of 109 particles of bacteriophage for each animal. $24 \mathrm{~h}$ after inoculation the difference in phage accumulation in tumor and in lungs attains significant values, from several dozens to several hundred times. Two phages, 12-2 and 7-3, showed the most effective results (Figure 1). Of note, 12-2 phage was isolated from Ph.D.-12 $2^{\mathrm{ma}}$ library, and phage 7-3 - from Ph.D.- $7^{\text {tru }}$ one (Figure 1).

It is believed that during the selection of tumor-specific peptides in vivo peptides are often selected that bind to growing tumor vessels whose antigenic features significantly differ from vessels of organism [15]. To verify this statement we studied capacity of selected phages to bind to other great tumor - hepatoma. To that end, we used animal models that simultaneously have two tumors (AL and HA). Mice were administered with 12-2 and 7-3 phages. Figure 2 shows that both 12-2 and 7-3 phages accumulate both in one and the other tumor in significantly large quantities compared to control phage. These data indicate that phage binds either to similar markers of cancer cell of two different tumors, or to vessels or other parts of tumor stroma.

We also analyzed interaction between phage clones $12-2$ and 7-3 and ascitic cells AL and did not detect significant differences between

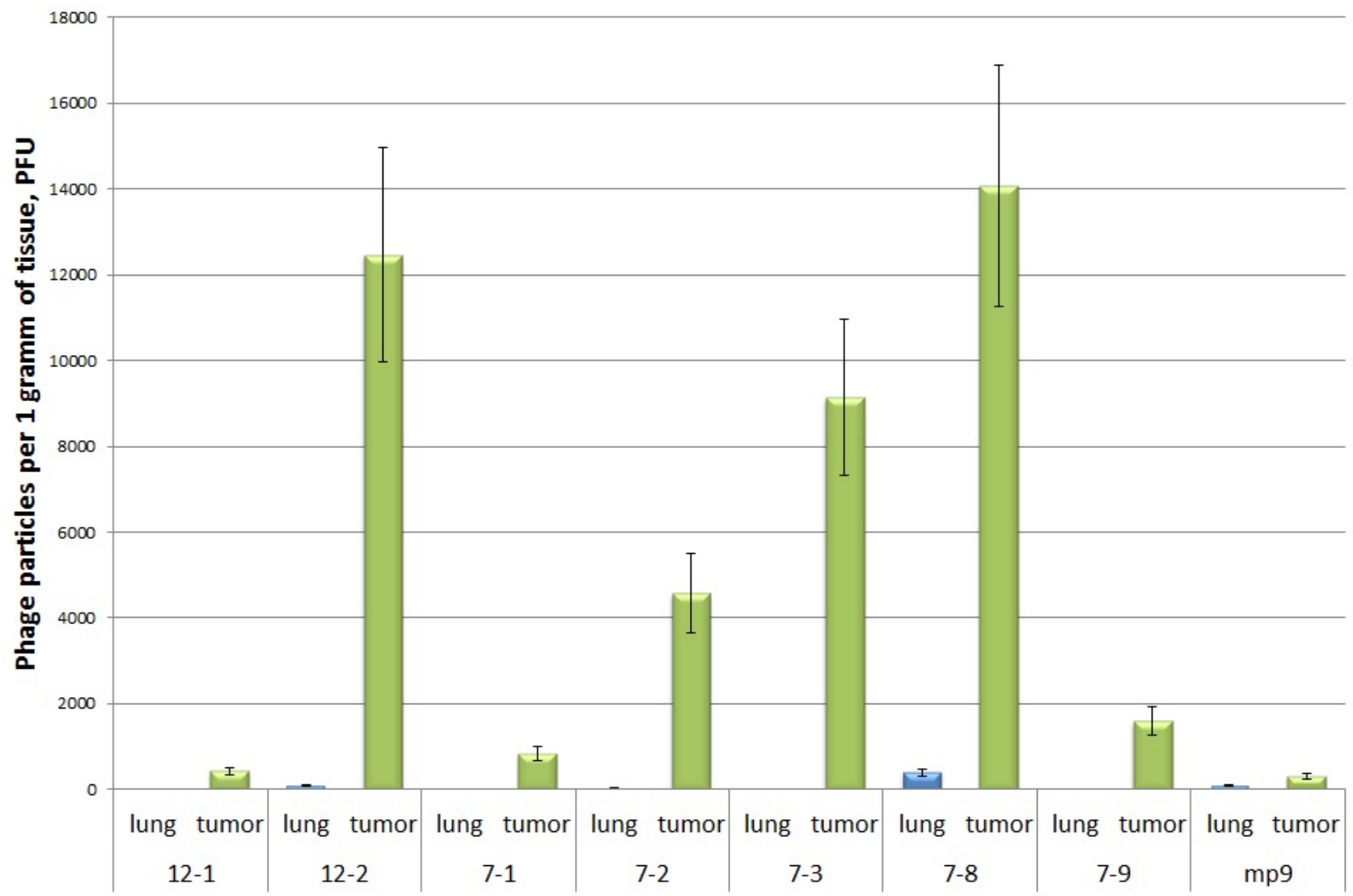

Figure 1: Accumulation of phage clones in organs (tumor and lungs) $24 \mathrm{~h}$ after inoculation of 109 phage particles into organism of mice with lung adenocarcinoma. Phage quantity is indicated in equivalent of $1 \mathrm{~g}$ of tissue. Three mice were used in experiment with each bacteriophage. 
Citation: Borgoyakova MB, Karpenko LI, llyichev AA (2015) Isolation And Studying of Specificity of Bacteriophages Binding To Murine Lung Adenocarcinoma. Biol Med S2: 002. doi: 10.4172/0974-8369.S2-002

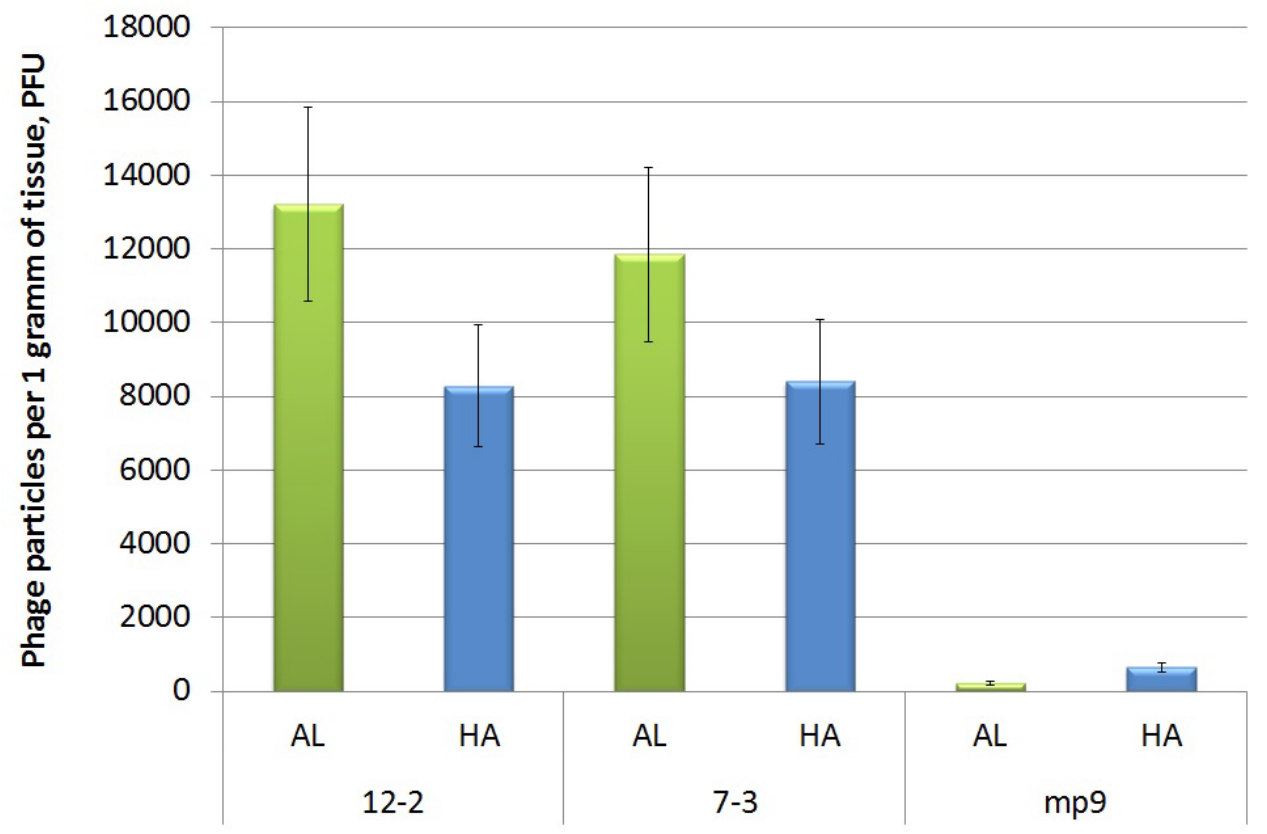

Figure 2: Binding of 12-2, 7-3 and control phages to lung adenocarcinoma and hepatocarcinoma in vivo $24 \mathrm{~h}$ after administration of 109 phage particles into organism of mice with both tumors. Phage quantity is indicated in equivalent of $1 \mathrm{~g}$ of tissue. Three mice were used in experiment with each bacteriophage.

ascitic cells with phages carrying insertion and the control phage. It confirms above-mentioned hypothesis that selection had place in growing vessels or other parts of tumor stroma, but not in tumor cells.

\section{Discussion}

Currently developed chemotherapeutic methods often enable to significantly decrease tumors, prevent back-sets and metastasis after surgical treatment. At the same time chemotherapy in oncology involves a lot of side effects, both temporary and long-term. The fact is that chemotherapeutic preparation action is focused on control of cancer cells; however, those drugs significantly influence on healthy cells activity. Therefore it is important to titrate down preparation administered to patient during treatment. It can be achieved by conjugation of peptides addressed to tumor with medicinal drug. In this case it can be possible to provide enhanced concentration of drug substance in region of tumor and consequently to significantly decrease action of chemotherapeutic agent on patient's organism. Peptide itself is virtually nontoxic. The use of such peptides conjugated with fluorochrome is possible for diagnostic purposes, for instance, for visualization of tumor before operation.

Of course, phage display similar to any other method has some disadvantages. The paper describes the most important issues.

While the concentration of phage particles sounds impressive and approaches $1012 / \mathrm{ml}$, the molarity of the displayed peptides is quite low (i.e., picomolar) and, therefore, biochemical experiments necessitate the use of synthetic forms of the peptides. The sequence complexity of the library is below that of the number of recombinants in a library and a negative result may be due to sparse sampling. There is biological selection against odd numbers of cysteines, runs of positive charges, and certain residues at fixed positions within the displayed peptide. Consequently, selection results may be inherently biased. Phage-display typically only yields binding or bioactive peptides that "work" and as a result one can only infer, from the absence of data, what does "not work". Thus, based on the last three limitations, phage-display is more of a survey tool, rather than an analytical one: whenever one isolates peptides of interest through phage-display experiments, it is generally beneficial to synthesize the isolated peptides, and sets of related sequences, for careful, qualitative and quantitative analysis [16].

However, phage display technique, using 12-mer and 7-mer phage peptide libraries by means of in vivo selection, enables us to select phage clones. After intravenous administration in mice those clones accumulated in mice tumor several dozens and hundred times as much as in control organs. The absence of specific binding of selected peptides to tumor cells in vitro, as well as their binding to different tumors in vivo enables to assume that studied phages demonstrate affinity most likely to growing blood vessels or other elements of stroma. We think that tumor-specific peptides capable to deliver phages to tumor can be used in practical medicine for targeted delivery of medicinal drugs and diagnostics.

\section{Acknowledgement}

This study was supported by the Ministry of Education and Science of the Russian Federation (Grant \# 303). Authors express thanks to Dr. V.I. Kaledin, Dr. V.P. Nikolin, and Dr. N.A. Popova from the Institute of Cytology and Genetics of Siberian Branch of the Russian Academy of Sciences for their assistance in the work with grafted tumors.

\section{References}

1. Brown KC (2010) Peptidic Tumor Targeting Agents: The Road from Phage Display Peptide Selections to Clinical Applications. Current Pharmaceutical Design 16: 1040-1054

2. Arap W, Pasqualini R, Ruoslahti E (1998) Cancer treatment by targeted drug delivery to tumor vasculature in a mouse model. Science 279: 377-380.

3. Miller SJ, Joshi BP, Feng Y, Gaustad A, Fearon ER, et al. (2011) In Vivo Fluorescence-Based Endoscopic Detection of Colon Dysplasia in the Mouse Using a Novel Peptide Probe. Plos One 6.

4. 4. Pasqualini R, Ruoslahti $E$ (1996) Organ targeting in vivo using phage display peptide libraries. Nature 380: 364-366. 
Citation: Borgoyakova MB, Karpenko LI, llyichev AA (2015) Isolation And Studying of Specificity of Bacteriophages Binding To Murine Lung Adenocarcinoma. Biol Med S2: 002. doi: 10.4172/0974-8369.S2-002

5. Zitzmann S, Mier W, Schad A, Kinscherf R, Askoxylakis N, et al. (2005) New prostate carcinoma binding peptide (DUP-1) for tumor imaging and therapy. Clin Cancer Res 11: 139-146.

6. Eriksson F, Culp WD, Massey R, Egevad L, Garland D, et al. (2007) Tumo specific phage particles promote tumor regression in a mouse melanoma model. Cancer Immunology Immunotherapy 56: 677-687.

7. Lee TY, Lin CT, Kuo SY, Chang DK, Wu HC (2007) Peptide-mediated targeting to tumor blood vessels of lung cancer for drug delivery. Cancer Res 67: 1095810965.

8. Krag DN, Shukla GS, Shen GP, Pero S, Ashikaga T, et al. (2006) Selection of tumor-binding ligands in cancer patients with phage display libraries. Cancer Res 66: 7724-7733.

9. Laakkonen P, Akerman ME, Biliran H, Yang M, Ferrer F, et al. (2004) Antitumor activity of a homing peptide that targets tumor lymphatics and tumor cells. Proceedings of the National Academy of Sciences of the United States of America 101: 9381-9386.

10. Krumpe LR, Mori T (2006) The Use of Phage-Displayed Peptide Libraries to Develop Tumor-Targeting Drugs. Int J Pept Res Ther 12: 79-91.
11. Loi M, Marchiò S, Becherini P, Di Paolo D, Soster M, et al. (2010) Combined targeting of perivascular and endothelial tumor cells enhances anti-tumor efficacy of liposomal chemotherapy in neuroblastoma. J Control Release 145 : 66-73.

12. Rivinoja A, Laakkonen $P$ (2011) Identification of homing peptides using the in vivo phage display technology. Methods Mol Biol 683: 401-415.

13. Wu CC, Lin EH, Lee YC, Tai CJ, Kuo TH, et al. (2010) Identification of a new peptide for fibrosarcoma tumor targeting and imaging in vivo. J Biomed Biotechnol 2010: 167045.

14. Kaledin VI, Matienko NA, Nikolin VP, Gruntenko YV, Budker VG (1981) Intralymphatic administration of liposome-encapsulated drugs to mice possibility for suppression of the growth of tumor-metastases in the lymphnodes. J Nat Cancer Ins 66: 881-887.

15. Ruoslahti E (2002) Specialization of tumour vasculature. Nat Rev Cancer 2 : 83-90.

16. Huang R, Pershad K, Kokoszka M, Kay BK (2011) Phage-Displayed Combinatorial Peptides. Amino Acids, Peptides and Proteins in Organic Chemistry: Wiley-VCH Verlag GmbH \& Co. KgaA, USA, 451-471.
This article was originally published in a special issue, Cancer Biology and Therapeutics handled by Editor. Tapasya Srivastava, University of Delhi

South Campus, India 